\title{
LUMBAR SPINAL STENOSIS
}

\section{THE CLINICAL SPECTRUM AND THE RESULTS OF OPERATION}

\author{
C. J. M. GETTY
}

From the Department of Orthopaedic Surgery, Norfolk and Norwich Hospital, Norwich

Thirty-one patients who had been treated surgically for lumbar spinal stenosis between 1968 and 1978 at the Norfolk and Norwich Hospital have been personally reviewed. In 28 patients (90 per cent) degenerative change in the lumbar spine had been the principal aetiological factor; the other three had idiopathic developmental lumbar spinal stenosis. In 17 patients (55 per cent) the result was classified as good, although a total of 26 patients (84 per cent) were satisfied. In patients with degenerative changes, one important reason for failure was inadequate decompression; re-operation in this group seemed worthwhile. The good results of operation, for lumbar spinal stenosis were characterised by rapid resolution of pain in the leg.

There are two aetiological concepts of lumbar spinal stenosis. Verbiest (1977) has emphasised idiopathic developmental factors as the primary cause, while Paine and Haung (1972) stress the importance of acquired lesions.

The previously published results of surgical treatment for this condition are variable, but different authors use different criteria for classification. Teng and Papatheodorou (1963) reported that 62 per cent of their patients were asymptomatic and fully employed after operative treatment. Paine (1976a) categorised his results into four groups on the basis of relief of pain and

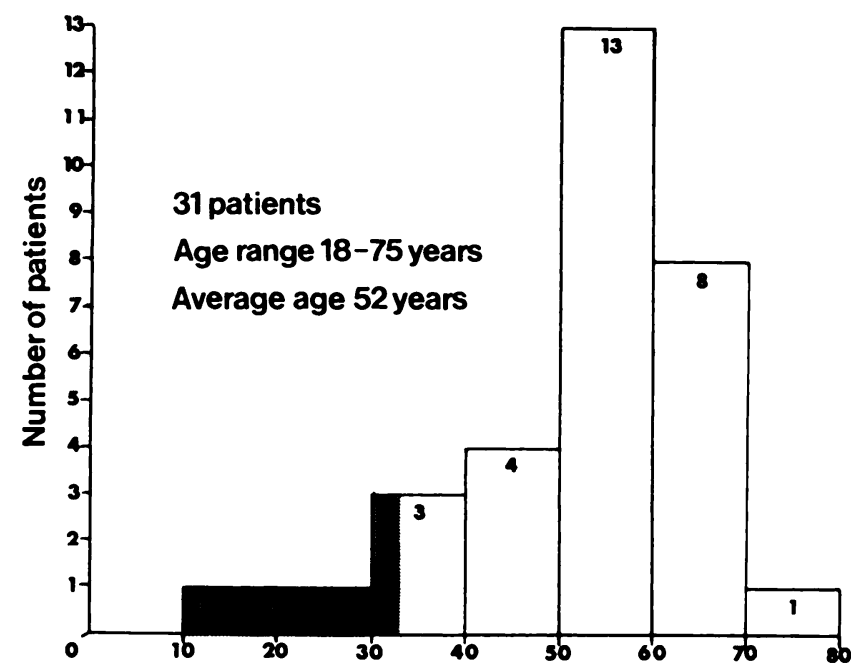

Age at onset of symptoms (years)

Fig. 1

Ages of 31 patients at the onset of spinal symptoms. The shaded areas represent the three with idiopathic developmental lumbar spinal stenosis. the current occupation, approximately 80 per cent of his patients returning to their normal occupations after operation. He also demonstrated that re-operation in patients with a previously inadequate decompression seemed worthwhile. Verbiest (1977), in his series of 147 cases of idiopathic developmental spinal stenosis collected over 27 years, found that about 66 per cent of his patients were completely relieved of symptoms and signs after decompression.

Smaller series have been reported from the United Kingdom. Jones and Thomson (1968) recorded 10 patients, of whom two were graded as good and seven as fair after an unspecified follow-up. Nelson (1973) reported nine patients with eight excellent results, but the average follow-up was only 11 months.

This retrospective study was undertaken to assess the results of treatment and to determine which factors are important in the selection and subsequent management of patients with lumbar spinal stenosis.

\section{MATERIAL AND METHODS}

Thirty-five patients were treated surgically for lumbar spinal stenosis at the Norfolk and Norwich Hospital between 1968 and 1978. Thirty-one of them were seen by the author after operation, and they form the basis of this study. Four patients were lost to follow-up.

There were 16 men and 15 women. The age at the onset of symptoms is shown in Figure 1. The mean time from the onset of symptoms to operation was 5.8 years. Each patient had been assessed and given a period of conservative treatment which included analgesia, physiotherapy, manipulations, epidural injections and the use of spinal supports, but in none had the symptoms improved. Two patients had had a laminectomy before the diagnosis of idiopathic developmental lumbar spinal stenosis was established. The mean follow-up was 3.5 years with a range of 1 to 10 years.

Assessment before operation. A detailed assessment of each patient had been made, taking particular note of the symptoms and signs of spinal disease. Occupational histories had been taken in the younger

C. J. M. Getty, FRCS, 5 Avon Way, Tavistock Road, South Woodford, London E18, England. 
patients, but the majority had been unable to work at the time of operation. In the elderly, the ability to continue with hobbies, for example walking and gardening, had been recorded; most had been unable to continue with them. Presenting symptoms and signs are summarised in Tables I and II. The two patients with disturbances of the bladder were admitted as emergencies with the cauda equina syndrome.

Table I. Presenting symptoms in 31 patients with lumbar spinal stenosis

\begin{tabular}{|l|c|c|c|}
\hline \multicolumn{1}{|c|}{ Symptoms } & Unilateral & Bilateral & $\begin{array}{c}\text { Total } \\
\text { number }\end{array}$ \\
\hline Pain & 10 & 18 & 28 \\
$\quad$ In low back and legs & 1 & & 2 \\
$\quad$ In low back only & & 1 \\
Claudication only & 3 & 5 & 8 \\
$\begin{array}{l}\text { Numbness or paraesthesiae } \\
\text { in thigh, calf or foot } \\
\text { Weakness in legs }\end{array}$ & 3 & 3 & 6 \\
Bladder disturbance & & & 2 \\
\hline
\end{tabular}

Table II. Presenting signs in 31 patients with lumbar spinal stenosis (with the percentage incidence)

\begin{tabular}{|c|c|c|c|c|}
\hline Signs & Unilateral & Bilateral & $\begin{array}{c}\text { Total } \\
\text { number }\end{array}$ & $\begin{array}{l}\text { Per } \\
\text { cent }\end{array}$ \\
\hline $\begin{array}{l}\text { Reflex deficit } \\
\text { Absent ankle reflex } \\
\text { Absent knee reflex }\end{array}$ & $\begin{array}{l}9 \\
3\end{array}$ & $\begin{array}{l}12 \\
-\end{array}$ & 22 & 71 \\
\hline $\begin{array}{l}\text { Sensory deficit } \\
\text { Impaired sensation for } \\
\text { light touch and pinprick } \\
\text { L4 dermatome } \\
\text { L5 dermatome } \\
\text { S1 dermatome } \\
\text { Saddle anaesthesia: } 2\end{array}$ & $\begin{array}{r}3 \\
14 \\
8\end{array}$ & $\begin{array}{l}0 \\
3 \\
2\end{array}$ & 18 & 58 \\
\hline $\begin{array}{l}\text { Motor deficit } \\
\text { Weakness and wasting } \\
\text { L4 root } \\
\text { L5 root } \\
\text { S1 root } \\
\text { Lax anal sphincter: } 2\end{array}$ & $\begin{array}{r}3 \\
14 \\
7\end{array}$ & $\begin{array}{l}0 \\
2 \\
2\end{array}$ & 16 & 52 \\
\hline $\begin{array}{l}\text { Spinal movements } \\
\text { Markedly reduced in all } \\
\text { directions }\end{array}$ & & & 12 & 39 \\
\hline $\begin{array}{l}\text { Straight leg raising } \\
\text { Less than } 30 \text { degrees }\end{array}$ & 4 & 3 & 7 & 23 \\
\hline
\end{tabular}

Each patient had had routine haematological and biochemical investigations. The spinal index (Jones and Thomson 1968) had been measured on radiographs of the lumbar spine. Myelography had been done and the results classified into the three broad groups of degenerative, mixed and developmental spinal stenosis according to the criteria of Kirkaldy-Willis et al. (1974).

The indications for operative treatment were pain, continual or intermittent, which caused significant functional disability, and which had not been relieved by conservative treatment; a progressive neurological deficit; and the cauda equina syndrome.

Operative technique. This consisted of a central laminectomy, extended laterally to decompress the nerve roots. Lateral decompression was performed by an undercutting partial facetectomy. Artificial laminectomy membranes were not used in this series, nor was the dura deliberately opened. Vacuum drainage was used in six patients. In none was a spinal fusion performed simultaneously or subsequently.

Each operation was performed by the consultant in charge of that particular patient.

Assessment after operation. All the patients were seen by the author. A comparison was made of their symptoms, signs and disability before and after treatment. The results were graded as shown in Table III.

Table III. Criteria for assessment after operation

\begin{tabular}{|l|l|}
\hline $\begin{array}{l}\text { Pain relieved } \\
\text { Continued in previous occupation or with } \\
\text { previous hobbies }\end{array}$ & GOOD \\
\hline $\begin{array}{l}\text { Partial relief of pain with temporary recurrence } \\
\text { after heavy work } \\
\text { Continued in previous occupation or with } \\
\text { previous hobbies, but exacerbations of pain led to } \\
\text { periods off work }\end{array}$ & FAIR \\
\hline $\begin{array}{l}\text { No relief of pain or increase in pain } \\
\text { Patient not working, not doing hobbies; } \\
\text { or only able to carry out light work }\end{array}$ & POOR \\
\hline
\end{tabular}

\section{RESULTS}

Investigations. No abnormalities were found in the haematological or biochemical investigations.

The spinal index was positive in 23 patients $(74$ per cent) but within normal limits in the remainder. There were six patients (19 per cent), all women, with degenerative spondylolisthesis, all at the L4-5 level.

Myelography indicated 20 patients (65 per cent) with degenerative lumbar spinal stenosis. The spinal canal was narrowed segmentally, the indentations being due to the degenerative changes which occurred mainly in the posterior joints and in the intervertebral discs. The anteroposterior diameter of the canal between these sites was relatively normal (Figs 2 and 3). There were eight patients ( 25 per cent) with degenerative stenosis in a developmentally narrowed canal-that is a mixed stenosis. The anteroposterior dimension of the canal at myelography was uniformly less than 14 millimetres over most of the lumbar spine. The superimposed degenerative changes produced a segmental pattern in the already narrowed canal (Figs 4 and 5). In these two groups there was stenosis at L4-5 in every patient.

Three patients (10 per cent) had idiopathic 


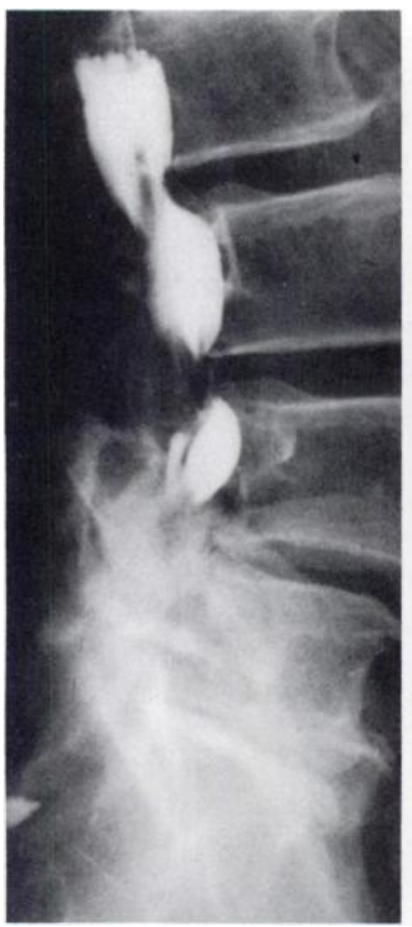

Fig. 2

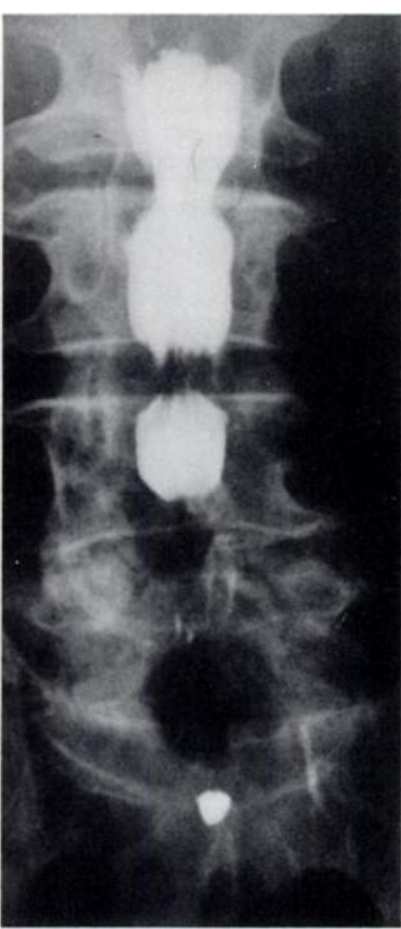

Fig. 3

Lateral and anteroposterior myelograms showing degenerative lumbar spinal stenosis at several levels in a woman aged 70 years.

developmental lumbar spinal stenosis. There was uniform narrowing over almost the whole length of the lumbar bony canal. The anteroposterior dimension of the canal, as determined by direct measurement of the lateral myelograms, was less than 14 millimetres throughout the lumbar spine (Figs 6 and 7).

Operative findings. The operative findings in the three broad groups of spinal stenosis were similar to those previously described (Schatzker and Pennal 1968; Kirkaldy-Willis et al. 1974).

The 20 patients in the degenerative group were all decompressed at L4-5; in addition, two were decompressed at L2-3, 14 at L3-4 and 12 at L5-S1. In the mixed group the L4-5 and L3-4 levels were decompressed in all eight patients, and L5-S1 in four. In the idiopathic group the decompression extended from L3-5 in two patients and L2-5 in one.

Complications. There were no operative complications. After operation four patients developed a deep venous thrombosis, and in one this was complicated by a pulmonary embolus; all responded satisfactorily to anticoagulant therapy. Urinary retention occurred in six patients, all of whom recovered when the catheters were removed and they were walking. There were two superficial wound infections.

Surgical results. The results of operation are shown in Table IV. Fifty-five per cent of all the patients achieved a good result. There was complete recovery of sphincter function in the two who presented with the cauda equina syndrome.

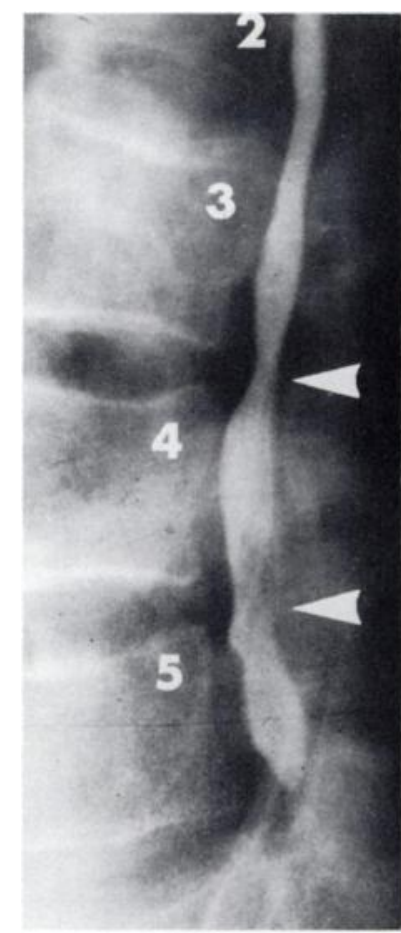

Fig. 4

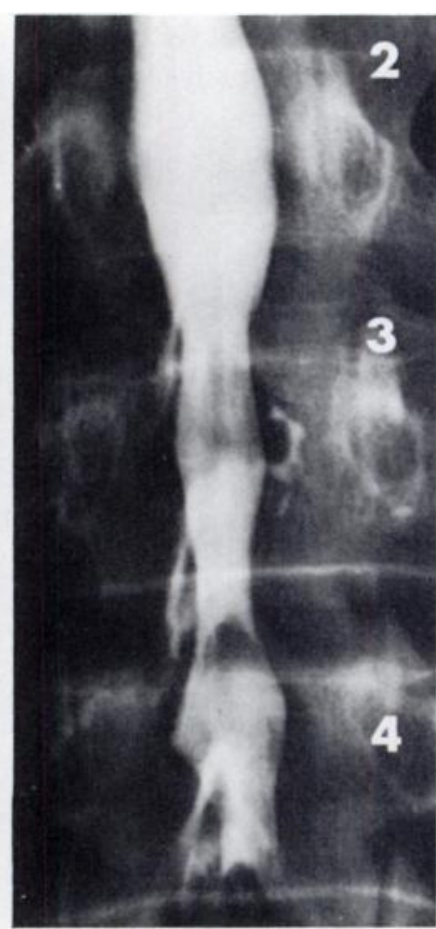

Fig. 5
Mixed stenosis, in a 70-year-old man. Posterior indentations are seen on the lateral myelogram (arrowed). Apparent non-filling below L4 in the anteroposterior view is due to the myelogram being taken before delayed filling had occurred.

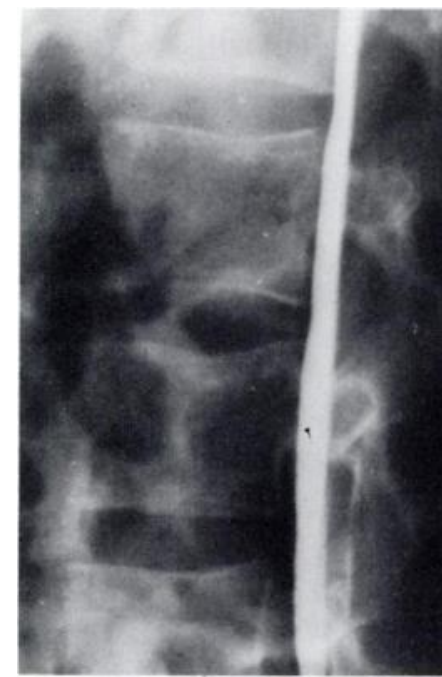

Fig. 6

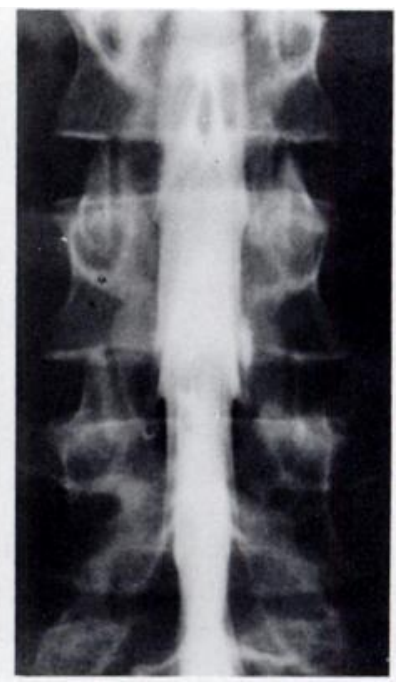

Fig. 7
Idiopathic developmental lumbar spinal stenosis in an 18-year-old man. On the prone lateral myelogram (Fig. 6) there is uniform narrowing in the anteroposterior dimension.

\section{DISCUSSION}

In this retrospective study analysis of the clinical spectrum indicated several interesting features. There was a long period between the onset of symptoms referable to the spine and the time of operation, the mean delay being 5.8 years (range 6 months to 30 years). Paine (1976b) has, however, quoted a delay of seven years when stenosis was secondary to degenerative 
change. I believe that this delay is partly due to the slowly progressive nature of the degenerative change in the lumbar spine, where symptoms and signs of lumbar spinal stenosis may be late manifestations, and partly due to the delay in reaching a specialist centre where a definitive diagnosis may be made. In this series the delay before surgical treatment was shorter than that reported by Paine, and may indicate an increased awareness of the diagnosis of lumbar spinal stenosis. It is all too easy to attribute pain in the back to degenerative changes symptoms most frequently relieved were pain in the leg and claudication, usually immediately after operation and certainly within three months. This, I believe, is a useful clinical pointer to prognosis, since the improvement was maintained for the whole follow-up period in all but three patients. In these three patients pain in the leg recurred spontaneously at one, three and eight years after treatment. There is no clear reason why these relapses occurred, their symptoms so far being insufficient to warrant further investigation.

Table IV. Results of treatment

\begin{tabular}{|c|c|c|c|c|c|c|c|}
\hline \multirow[b]{2}{*}{ Group } & \multirow[b]{2}{*}{$\begin{array}{l}\text { Number of } \\
\text { patients }\end{array}$} & \multicolumn{6}{|c|}{ Results } \\
\hline & & Number & $\begin{array}{l}\text { od } \\
\text { Per cent }\end{array}$ & Number & $\stackrel{\text { Ir }}{\text { Per cent }}$ & Number & $\begin{array}{l}\text { or } \\
\text { Per cent }\end{array}$ \\
\hline Degenerative spinal stenosis & 20 & 11 & 55 & 5 & 25 & 4 & 20 \\
\hline Mixed spinal stenosis & 8 & 4 & 50 & 3 & 38 & 1 & 12 \\
\hline Developmental spinal stenosis & 3 & 2 & 67 & 1 & 33 & 0 & - \\
\hline
\end{tabular}

The percentage represents that within each group

seen radiologically, without a careful history and examination. When the patient was examined, the physical signs that were most useful in the diagnosis of lumbar stenosis were reflex deficit, impaired sensation and motor weakness in the legs (see Table II). Weinstein, Ehni and Wilson (1977) have reported a similar incidence of physical findings, although in their series motor weakness was more frequent than sensory deficit. Seven patients showed a positive result in the stoop test (Dyck 1979) and a further seven a reduction in straight leg raising ability, suggesting that both tests were of limited value.

In this series there was an equal sex distribution whereas previous studies have shown a male predominance (Jones and Thomson 1968; Roberson, Llewellyn and Taveras 1973). No familial or occupational predisposition to the development of this condition could be elicited from the patients' histories.

The incidence of good results (see Table IV) was 55 per cent. In addition, nine patients ( 29 per cent), who were grouped as fair, were satisfied with their operative result, so that the total percentage of satisfactory results was 84 per cent. All these patients returned to their usual occupations or hobbies. These figures do not differ from previous reports. Teng and Papatheodorou (1963) reported that 62 per cent of their patients were asymptomatic and fully employed after operative treatment, and Paine (1976a) reported that approximately 80 per cent of his patients had returned to their usual occupations or hobbies after operation.

Fourteen of the 17 patients who gained a good result described a rapid resolution of pain. The
A further two patients in the good category had a laminectomy before the definitive diagnosis was reached. The original diagnosis in both was prolapsed intervertebral disc, but their symptoms were not relieved by hemilaminectomy and excision of the disc. The definitive diagnosis was idiopathic developmental lumbar spinal stenosis which, in retrospect, could be seen on the original myelograms. Subsequent multilevel decompression totally relieved the symptoms. The original operation notes described an absence of epidural fat, a tight canal and a minimally bulging disc. Although idiopathic developmental spinal stenosis is uncommon, it is important always to consider this diagnosis at operation, particularly if the operative findings are unusual.

Originally seven patients ( 22.5 per cent) obtained a poor result. Their definitive diagnosis was degenerative or mixed spinal stenosis but their symptoms had not been relieved by a central multi-level decompression. The probable reasons for this were inadequate decompression and the very marked degenerative changes in the lumbar spine found in all these patients. Four of the seven had a further exploration at which it was found that there had been an inadequate lateral decompression at the initial procedure. After re-operation two of them were unchanged but two obtained a fair result. These failures were probably due to the arachnoiditis noted in the radiculograms before operation and the dense fibrosis and degenerative changes found at operation. Compression of the nerve root over many years before operation, with stretching and probable ischaemia, may be irreversible despite an adequate 
central and lateral decompression. This may be an important additional factor in causing persistent pain and disability. The findings are in keeping with Paine's reports on the outcome of re-operation (1976a). Moreover, they emphasise the importance of performing an adequate lateral decompression at the first operation (Schatzker and Pennal 1968; Wiltse, Kirkaldy-Willis and McIvor 1976). Verbiest (1977), however, has emphasised the dangers of "too generous a decompression".

Even after adequate decompression had been achieved the degenerative changes found in this group of patients remained, giving rise to low backache. It is important to advise patients before operation that they are likely to have some pain afterwards. Patients who are thus prepared psychologically do have a more balanced approach to their situation. These poor results were characterised by persistent low backache in all patients, by sciatica, usually with a sensory or motor deficit or both, in the L5 and S1 root distribution, and by persistent claudication in most of the patients. There was little or no relief of symptoms in the convalescent period or subsequently.

It is evident that a diagnosis of lumbar spinal stenosis must always be included in the differential diagnosis of low back pain, especially when this is associated with bilateral sciatica. In the younger patient the possibility of idiopathic developmental lumbar spinal stenosis must be considered. Patients over the age of 50 years who have degenerative changes causing lumbar spinal stenosis have a good prognosis after an adequate primary decompression, and in our experience rapid resolution of pain in the leg usually indicates a good surgical result.

I would like to thank Mr R. C. Howard, Mr J. G. Taylor, Mr J. Watson-Farrar, and Mr H. Phillips for allowing me to study their patients at the Norfolk and Norwich Hospital; Mr E. O. Kirwan and Dr J. Winfield for help with the manuscript; Dr D. Stoker and Dr P. Renton for assistance with the myelograms; Miss Sheila Grant for organising the clinics; and the Photographic Department at the Royal National Orthopaedic Hospital for the prints.

\section{REFERENCES}

Dyck P. The stoop-test in lumbar entrapment radiculopathy. Spine 1979;4:89-92.

Jones RAC, Thomson JLG. The narrow lumbar canal. J Bone Joint Surg [Br ] 1968;50-B:595-605.

Kirkaldy-Willis WH, Paine KWE, Cauchoix J, McIvor G. Lumbar spinal stenosis. Clin Orthop 1974;99:30-50.

Nelson MA. Lumbar spinal stenosis. J Bone Joint Surg [Br ] 1973;55-B:506-12.

Paine KWE. Results of decompression for lumbar spinal stenosis. Clin Orthop 1976a;115:96-100.

Paine KWE. Clinical features of lumbar spinal stenosis. Clin Orthop 1976b;115:77-82.

Paine KWE, Haung PWH. Lumbar disc syndrome: J Neurosurg 1972;37:75-82.

Roberson GH, Llewellyn HJ, Taveras JM. The narrow lumbar spinal canal syndrome. Radiology 1973;107:89-97.

Schatzker J, Pennal GF. Spinal stenosis, a cause of cauda equina compression. J Bone Joint Surg [Br ] 1968;50-B:606-18.

Teng P, Papatheodorou C. Lumbar spondylosis with compression of cauda equina. Arch Neurol 1962,8:221-9.

Verbiest H. Results of surgical treatment of idiopathic developmental stenosis of the lumbar vertebral canal. J Bone Joint Surg [Br] 1977;59-B:181-8.

Weinstein PR, Ehni GJ, Wilson CB. Lumbar spondylosis, diagnosis, management and surgical treatment. Chicago: Year Book Medical Publishers Inc, 1977:115-33.

Wiltse LL, Kirkaldy-Willis WH, McIvor GWD. The treatment of spinal stenosis. Clin Orthop 1976;115:83-91. 